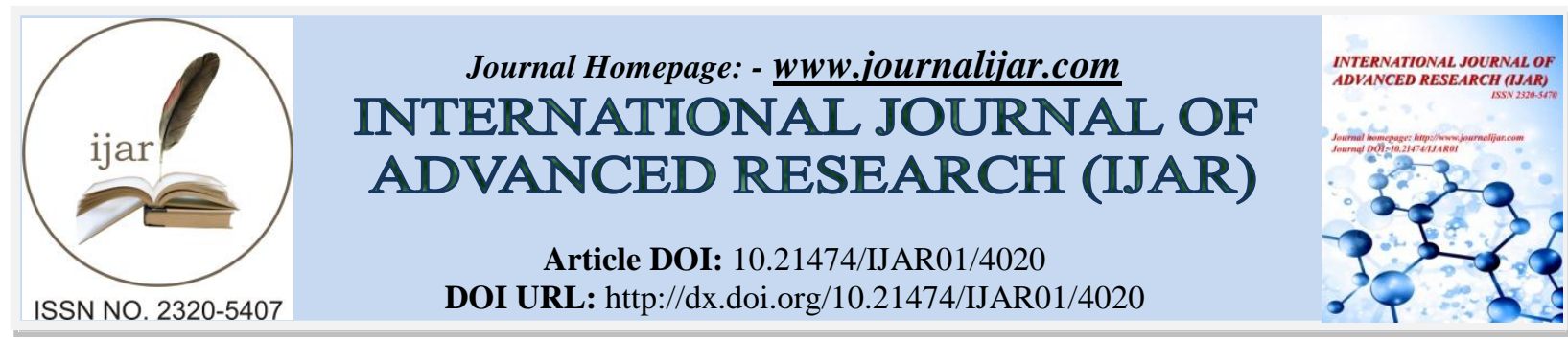

RESEARCH ARTICLE

\title{
URINARY TRACT INFECTION IN PREGNANCY: WHAT IS THE PREVALENCE OF ASYMPTOMATIC BACTERIURIA DURING PREGNANCY AND ITS CAUSATIVE AGENTS AND THEIR SENSITIVITY.
}

\section{Dr. Sanjana N Wadhwa ${ }^{1}$ and Dr. Naimaa K Choudhary ${ }^{2}$.}

1. Department of Obstetrics and Gynecology, ESIC Post Graduate Institute of Medical Sciences and Research, Basaidarapur, Delhi 1 I0015 India.

2. Department of Obstetrics and Gynecology, St. Stephens Hospital, Tis Hazari Delhi, 110054 India.

\section{Manuscript Info}

(..........................

Manuscript History

Received: 24 February 2017

Final Accepted: 18 March 2017

Published: April 2017

\section{Abstract}

Urinary tract infections are most common medical complication in pregnancy and most common among this is pyelonephritis. The combination of hormonal and physiologic changes during pregnancy contributes to significant changes in urinary tract, which has a profound impact on the acquisition and natural history of bacteriuria during pregnancy. The prevalence of asymptomatic bacteriuria is high among antenatal women in India. It leads to various complications in Antenatal period. Causative agents and their sensitivity to drugs vary in different region. In India, screening of asymptomatic bacteriuria is not considered an essential part of antenatal care like routine check-up for albumin and sugar in urine. These tests have poor positive and negative predictive values to detect bacteriuria in asymptomatic bacteriuric persons. Urine culture and sensitivity is considered as the gold standard to detect asymptomatic bacteriuria. The proper screening and treatment of bacteriuria during pregnancy is necessary to prevent complications. Therefore for appropriate treatment, it is required to stay abreast of information about the pathogens and their sensitivity.

Thus it is recommended to obtain a urine culture in pregnant women and in whom asymptomatic bacteriuria detected should be treated with antibiotics targeting the cultured organisms and they should undergo follow-up monitoring.

Copy Right, IJAR, 2017,. All rights reserved.

\section{Introduction:-}

Urinary tract infections as a group are the most common medical complication of pregnancy. Urinary infection (UTI) refers to both microbial colonization of the urine and tissue invasion of any structure of urinary tract. Most common causative organisms belong to bacteria. In asymptomatic bacteriuria, the patient does not have symptoms of urinary tract infections but urine culture reveals a significant growth of pathogens, that is greater than $10^{5}$ bacteria/ml ${ }^{(1)}$. Normal urine is sterile. It contains fluids, salt and waste products but it is free of bacteria, viruses and fungi. Pregnant urine is an even more suitable culture medium, than the non-pregnant because the $\mathrm{pH}$ is higher than 6.

Asymptomatic bacteriuria can be found in both pregnant and non-pregnant women. Bacteriuria in pregnancy has a greater propensity to progress to pyelonephritis in up to $40 \%$ cases than in non-pregnant women. Pregnancy enhances the progression to pyelonephritis and leads to adverse obstetric outcomes. ${ }^{(1)}$

Corresponding Author:- Dr. Sanjana N Wadhwa.

Address:- Department of Obstetrics and Gynecology, ESIC Post Graduate Institute of Medical Sciences and Research, Basaidarapur, Delhi 1 I0015 India. 
Urine culture is considered as the gold standard test to detect asymptomatic bacteriuria. Pregnant women should be screened for asymptomatic bacteriuria in the first trimester of pregnancy. Thus the aim of this study was to estimate the prevalence of asymptomatic bacteriuria in pregnancy and its etiological agents and their sensitivity pattern in the pregnant women attending antenatal clinics of St. Stephen's Hospital.

\section{Materials and Methods:-}

This was a prospective study which was undertaken at the Department of Obstetrics and Gynecology of St. Stephen's Hospital, Tis Hazari, Delhi. All pregnant women attending antenatal clinic were assessed for asymptomatic bacteriuria between November 2008 to October 2009. Verbal informed consent was obtained from each patient prior to sample collection.

The study excluded any pregnant woman who had any known congenital anomalies of urinary tract, history of preexisting UTI prior to any active sexual life, history of antibiotics during the previous two weeks or history of catheterization during past two weeks.

The pregnant women were clinically evaluated to exclude signs and symptoms of urinary tract infection i.e. two or more of following complaints: dysuria, urinary hesitancy, urgency, slow stream, incontinence frequency, incomplete voiding and flank, suprapubic or hypogastric pain.

In all pregnant women a complete general (Blood, Pressure, Pulse rate and temperature) and obstetrical examination was performed after careful elicitation of the history.

After being instructed on the correct mode of self collection of urine sample i.e. open sterile cup and place it at easy reach. Separate the labia with one hand. With the other hand clean the genital area with water from front to back. While still holding the labia open pass a bit of urine into the toilet and catch the rest into the cup. They were provided with sterile universal bottles.

Samples of 30-50 ml urine were obtained and placed in a cold box. Each sample was microscopically examined for pus cells, bacteria and ova and then cultured within two hours. Urine samples that were not cultured within two hours were stored at $4^{0} \mathrm{C}$.

Urine culture is a semi quantitative analysis. Samples were cultured on dried plates of Cysteine lactose electrolyte deficient agar (CLED) media using a calibrated loop delivery $0.01 \mathrm{ml}$ of urine. One colony was equal to 100 $\mathrm{CFU} / \mathrm{ml}$. Plates were incubated aerobically at $37^{\circ} \mathrm{C}$ overnight. Colony counts yielding bacterial growth of $10^{5} / \mathrm{ml}$ or more of pure isolates were deemed significant. Isolates were identified to species level using standard methods. Isolates antimicrobial sensitivities were done using Kirby Bauer disc diffusion technique. Urine samples producing non-significant and mixed growths did not have the test repeated.

\section{Identification and Counting of bacterial colonies:-}

In each type of colony, the growth was identified by routine gram staining and biochemical reactions. In this study, the serial dilution techniques for quantitative culture was employed which is by far most accurate and the urine was collected by mid stream clean voided method.

Taking each colony to represent the growth of one bacterium, the colonies were counted when discrete and easily countable. The maximum number of colonies on each plate were counted and multiplied by dilution factor to represent the number of bacteria per milliliter of an uncentrifuged sample of urine.

\section{Antibiotic sensitivity test:-}

The organism isolated by routine culture from significant bacteriuric was subjected to antibiotic sensitivity tests by Kirby Bauer disc diffusion technique. In this, Muller Hilton medium is used, in it 4-5 colonies are incubated for half an hour to an hour. Then a carpet is made- lawn cultures in which disc are applied within fifteen minutes and incubated at 37 Celsius for 18-24 hours. The diameter of zone of inhibition around the disc was measured and the degree of sensitivity is graded.

\section{Result:-}


515 pregnant women were investigated for bacteriuria of these, 355 women were asymptomatic in so far as, symptoms referable to urinary tract infections were concerned. On quantitative urine culture the high bacterial counts over $1,00,000$ were observed in 10.7 percent specimens. The bacterial counts in these patients were above 100,000 organisms per $\mathrm{ml}$ of urine for the purpose of analysis.

87.3 percent samples were completely sterile and 1.97 percent had mixed intermediate counts between 10,000 and 1 , 00,000 organisms per ml.

\section{Organism Isolated:-}

In 355 samples of urine examined, 45 specimen yielded one or more organisms.

Escherichia Coli was found to be the most predominant organisms $55.26 \%$. The other organisms isolated in order of frequency were Klebsiella species $15.78 \%$. Table 1

\section{Antibiotic Sensitivity:-}

The antibiotic sensitivity pattern of the organisms isolated from the patients was studied and indicated in Table 2 . The overall antimicrobial susceptibility pattern showed Nitrofurotoin to be the most effective antibiotic.

\section{Discussion:-}

Urinary tract infections are most common medical complication occurring in pregnancy. The anatomical changes in the Urinary tract during pregnancy make it more prone to infection. Asymptomatic bacteriuria occurs in 2 to 7 percent of pregnant women. ${ }^{(2)}$

It is recommended to screen all antenatal women for asymptomatic bacteriuria and to treat all positive cases with antibiotics. Bacteriuria in pregnancy has a greater propensity to progress to pyelonephritis in up to $40 \%$ cases than in non-pregnant women. ${ }^{(2)}$.This risk is reduced by 70 to 80 percent if bacteriuria is eradicated ${ }^{(2)}$ with appropriate antibiotic treatment.

Urine culture and sensitivity is the gold standard test for screening and identification of bacteriuria. ${ }^{(3)}$ Ideally all pregnant women should be screened for asymptomatic bacteriuria in the first trimester of pregnancy. Evidence rating $\mathrm{A}$ (consistent, good quality, patient oriented evidence). (3) (4)

Single clean catch urine culture at the end of the $1^{\text {st }}$ trimester (12-16 weeks gestation) generally is recommended.

The Canadian National Task Force on preventive health care and the American College of Obstetricians and Gynaecologists recommend screening urine cultures to detect asymptomatic bacteriuria during pregnancy as a routine basis. ${ }^{(3)}$

There is a strong association between untreated asymptomatic bacteriuria and low birth weight and preterm delivery and that antibiotic treatment is effective in reducing the occurrence of the complications associated with bacteriuria.

Incidence of symptomatic bacteriuria decreases by $80 \%$ - 90\% if asymptomatic bacteriuria is effectively treated during pregnancy. ${ }^{(5)(6)}$ Antimicrobial treatment of asymptomatic bacteriuria also decreases pregnancy related fetal complications. Pregnant woman who have asymptomatic bacteriuria should be treated with antimicrobial therapy for 3 to 7 days. ${ }^{(7)(8)}$

In our study, quantitative urine culture in 38 asymptomatic women during their first visit showed that $10.7 \%$ were exerting significant number of bacteria. Thus the estimated high prevalence of asymptomatic bacteriuria among the pregnant mothers of urban Delhi suggested that it will be very much worthwhile and cost-effective to screen the pregnant mothers for asymptomatic bacteriuria. The results of this study indicated that the pattern of isolated pathogens causing asymptomatic bacteriuria was the same as symptomatic bacteriuria even in pregnancy.

310 out of 355 samples were completely sterile; the remaining yielding growth of some organisms, isolation of obvious contaminants was ignored. In view of the earlier discussion, the results of urine culture with counts of more than 100,000 organisms per $\mathrm{ml}$ were considered significant for analysis of frequency of isolation.

A total of 10 strains were isolated from 38 samples with those counts (Table 1). 
Escherichia coli is the most predominant organism isolated from such samples, followed by organism of Klebsiella species. Proteus species, Staphylococcus and Alcaligenes faecalis.

The organisms isolated from these patients, their antibiotic sensitivity pattern was studied and indicated in Table 2. After administration, suitable antibiotics for a period two weeks, urine samples become sterile.

\section{Conclusion:-}

Asymptomatic bacteriuria is common in pregnant women. Thus, screening for asymptomatic bacteriuria and appropriate treatment should be considered as an essential part of antenatal care. Urine Culture and Sensitivity should be done in antenatal women in early trimester. Escherichia coli is the most common organism isolated from urine samples. Antibiotic therapy should be administered for a proper duration to be effective on the organism and it should be safe for the foetus.

\section{References:-}

1. Nicolle LE, Bradley S, Colgan R, et al. Infectious Diseases Society of America guidelines for the diagnosis and treatment of asymptomatic bacteriuria in adults. Clin Infect Dis 2005; 40:643.

2. Smaill FM, Vazquez JC. Antibiotics for asymptomatic bacteriuria in pregnancy. Cochrane Database Syst Rev 2015; :CD000490.

3. Thakur A et al ${ }^{1}$, Baral $\mathrm{R}^{2}$, Basnet $\mathrm{P}^{1}$, Rai $\mathrm{R}^{1}$, Agrawal $\mathrm{A}^{1}$, Regmi $\mathrm{MC}^{1}$. Asymptomatic bacteriuria in pregnant women. JNMA J Nepal Med Assoc. 2013 Oct-Dec;52(192):567-70.

4. US preventive services task force. Guide to clinical preventive services:2014. Agency for healthcare research and quality, Rockville, MD.

5. Harris RE. The significance of eradication of bacteriuria during pregnancy. Obstet Gynecol 1979; 53:71-73.

6. Norden CW, Kass EH. Bacteriuria of Pregnancy: a critical appraisal. Ann Rev Med. 1968; 19: 431-470

7. Widmer M, Lopez I, Gülmezoglu AM, et al. Duration of treatment for asymptomatic bacteriuria during pregnancy. Cochrane Database Syst Rev 2015; :CD000491.

8. Lumbiganon $\mathrm{P}^{1}$, Laopaiboon $\mathrm{M}$, Thinkhamrop J. Screening and treating asymptomatic bacteriuria in pregnancy.Curr Opin Obstet Gynecol. 2010 Apr;22(2):95-9. 